\title{
Bridging the Gap between Academic and Practice Quantity Surveying in Nigerian Construction Industry
}

\author{
Tawakalitu Bisola Odubiyi ${ }^{1 *}$, Douglas Aghimien ${ }^{1}$, Clinton Aigbavboa $^{1}$, and Wellington Thwala ${ }^{1}$ \\ ${ }^{1}$ SARChl in Sustainable Construction Management and Leadership in the Built Environment, \\ Faculty of Engineering and the Built Environment, University of Johannesburg \\ *Corresponding author's e-mail: kalitutawa@gmail.com
}

\begin{abstract}
In the construction industry worldwide there is a recognizable gap between academics construction knowledge and its application, and construction knowledge and application as seen in field of practice. In Nigeria, the Quantity surveying profession like other professions in the industry, suffers this same fate. It is based on this that this paper identified the possible factors causing gap between the two divisions. A survey approach was adopted, and questionnaire was used to gather data from construction professionals both in practice and in academics, Ondo State. Data gathered were analyzed using percentage, mean item score and Mann-Whitney U Test. Findings revealed that the major factors contributing to gap are majorly more theoretical knowledge than practical, inadequacy in educational curriculum, slow adoption of innovations and inadequate trained personnel. The two categories of respondents( practicing respondents and those in academics) believes that the most important factor that can help and in bridge the gap between QS in Academics and QS in practice is frequent organizing workshop, lectures and seminars which has been identified by past literature. Openness to new innovations, equilibrium of theoretical and practical knowledge, are the closely following factors. This study contributes to body of knowledge on this subject of discuss.
\end{abstract}

\section{KEYWORDS}

Quantity Surveying (QS); Academics; Field; Practice; Gap; Construction Industry

\section{INTRODUCTION}

On a global scale, competition helps service industries to strive towards better productivity. The construction industry like other germane sector of the economy is built on education and training, Quantity Surveying being one of such. Evidence showed that QS profession dates back to the 19th century (Akintayo et al., 2012). A report by United Nations Educational, Scientific and Cultural Organization (UNESCO) / United Nations Development Programme (UNDP) gave a detailed information on the history of Quantity surveying profession and education in Nigeria (UNESCO/UND, 1987). It related the qualifications of Quantity Surveyors from UK to the need for improving quantity surveying courses thought in only four schools Amadu Bello University Zaria (producing only 15 graduates), Yaba college of Technology, Lagos, Kaduna Polytechnic, and Auchi Polytechnic (producing about 45 OND graduates in all). Therefore there should be a quest for larger Quantity Surveying education provider. 
In present day Nigeria, there are various public and private institutions offering QS education. Describing such system from the angle of a developed country, the Department of Building and Real Estate (BRE) in Hong Kong is saddled with the responsibility of providing surveying academic programs in built environment and has been producing graduates for over 30years (Wong et al., 2007). Sri Lanka which is also a developing country in Asia has a system for Quantity surveying such as Honors programs awarded by Universities, National Certificate in Technology(Qs) offered by technical colleges, QS Technical Diploma, QS and Estimating among others (Paranawithana, 2014). Although there is boom in QS education which is proportional to the industry professionals there are some industrial setbacks.

It is observed that the expectations from QS education which is directly proportional to QS practice is low, as such, there is a gap. For instance, changes brought by the 21 st century calls the QS to respond to newer roles in the profession (Oke et al., 2013). Quantity Surveying Education in Nigeria has evolved overtime. Evidence showed that there are currently there are 19 polytechnics and 36 universities offering QS course in Nigeria (Olanrewaju et al., 2012). Historically, this program is traced to United Nations Educational, Scientific and Cultural Organization (UNESCO) / United Nations Development Programme (UNDP) (1987) which states that quantity surveying courses were only thought in only four schools Amadu Bello University Zaria (producing only 15 graduates), Yaba college of Technology, Lagos, Kaduna Polytechnic, and Auchi Polytechnic (producing about 45 OND graduates in all) as at 1976. This implies that QS education has expanded overtime and widened it scope.

The present day work place has call for strong academic syllabus to meet its current need. The history of QS syllabus/ curriculum can also be traced. United Nations Educational, Scientific and Cultural Organization (UNESCO (2001) gave a publication on syllabus and curriculum for quantity surveying education on the National Diploma level. Ghana, another developing African country, like Nigeria has its Quantity surveying education in the style of Britain which is her colonial master. However, curriculum designed for QS education in a developed world like Hong Kong is considered inadequate to meet up with modern development in the opinion of (Wong et al., 2007). For instance there is danger posed by curriculum of QS education in South Africa since it is stagnant and not meeting up with industrial expectation (Souza and Thwala, 2013). The educational sector should therefore develop strategies that would help the academic modules meet up with industrial needs.

The history of QS practice in Nigeria can be traced to Post independence. Evidence from Nigeria Institute of Quantity Surveyors (NIQS) shows that a regulatory body called Nigerian Institute of Quantity Surveyors was formed in1969 (NIQS, 2004). This was upon the return of Nigerians who had Quantity surveying education in the UK and also gained industrial experience there. The NIQS was formed as an image the of its mother body the Royal Institute of Chartered Surveyors (RICS) of the UK (Oke et al, 2013). Before this time, a report by United Nations Educational, Scientific and Cultural Organization (UNESCO) / United Nations Development Programme (UNDP) gave a history of Quantity surveying practice in Nigeria. The report stated that the profession was in United Kingdom before the Second World War although it was only in the form of expatriates officials in government administration. Private quantity surveying firm from the United Kingdom where established after the second world war such that promising staff from Nigeria were sent to the United kingdom to further train and qualify professionally. This professionals returned to 
Nigeria in 1958 according to United Nations Educational, Scientific and Cultural Organization (UNESCO) / United Nations Development Programme (UNDP) (2004). This explains the journey of QS professional practice in Nigeria.

Upon the return of these professionals a regulation body was formed to define the profession. Quantity surveying profession was first recognized by the regulated Miscellaneous Provision of Act 1978 as one of the scheduled professions in Nigeria (Oke et al., 2010). Also, according to Nigerian institute of Quantity Surveyors (NIQS), (2004) the Quantity Surveyors Registration Board of Nigeria (QSRBN) was formed under the decree No 31 of 1986. This is an umbrella under which QS practices are controlled. A Quantity surveyor is therefore defined as construction cost experts who plans, controls projects, serve as contract manager and negotiate tendering and budgets (Jagboro, 2016).

Quantity surveying practice have evolved with time. There have been noticeable changes in practices such as procurement, project management, ICT which has a relationship with academic line of Quantity Surveying. Therefore, complexity of modern construction necessitates specialization (Ameh and Odusami, 2014), as such there is a core relationship between academic trainings for Quantity surveyors and their field practices. The duties of a QS as they are seen from inception to completion of a project while they performs tasks like serving as financial adviser, procurement officer and value manager (Olanrewaju and Anahve, 2015). Quantity surveying education usually takes about five years to complete in Nigerian universities and Polytechniques.

In the process of training, all aspects of the profession will be taught, only a successful vetting of knowledge acquired by students will qualify them for the award of Bachelor of Science, Bachelor of Technology, or High National Diploma. It has however been noticed that Quantity surveying practice is evolving due to evolving construction. Evidence suggest there is a need for Fundamental knowledge for Quantity Surveyors' formal education. This will be later needed in the industry (Olanrewaju and Anahve, 2015). There is a gap in knowledge of building services which has negative toll on QS in the industry (Oke, et al, 2010). Therefore it is important the profession meets up with globalization in terms of study and practice.

Quantity surveying education must tally with industry needs. Evidence from Sri-Lanka points to this, (Yogeshwaran, et al., 2018). In South Africa, it was also recognized that there are problems faced by employers and Quantity surveying students since employers face students who are not well equipped for workplace and students equally have challenges with their taught program (Souza and Thwala, 2013). In support, it is expected that there should be sound education, "onthe-job" training and experience for quantity surveying education which will in turn affect a firm's success (Smith, 2001). This will influence the gap between theoretical and practical knowledge. In Nigeria, a scheme termed as SIWES is to introduce students to field work, the program usually last for six to twelve months, this is considers a short period to learn.

The output of learning determines the output at work place. It was observed that Nigerian Quantity Surveyors should be concerned in their discharging their duties (Oke, et al., 2010). This can be done by going for further education and training for both in academics and practice. it was also observed that older generation of QS are well grounded in costing, cost control and monitoring than the present day QS (Olusoga (2006). Also, in Hong Kong construction industry. Some skill 
or knowledge sect of quantity surveying students are either same or inferior to their predecessors (Wong et al., 2007). This is traceable to quality of academic knowledge gained these days and disposition of students to learning. This is definitely, a stumbling block to Qs productivity.

The problem of productivity can be attributed to several factors. There is a need for performance evaluation as it relates to productivity (Oke, et al., 2010). There are several factors attributed to productivity. For instance, technology has effect on clients need and project delivery method (Odubiyi and Oke, 2016; Usman, 2012). Hence, construction professionals should be more flexible and open to new innovation by technology (Odubiyi and Oke, 2016). This is to meet up with the present age of globalization. In the light of this, courses in academics should be reinforced to teaching of ICT related innovations used in the construction industry, an example of which is the Building information model. Knowledge from academics will be able to prepare quantity surveyors for field experiences.

Another perspective of quantity surveyors role as is project or site manager. there is change in the fundamental education of built environment professionals in project management division (Ameh and Odusami, 2014). The work further reveals that there are deficiency in project management related courses, however, some of these courses can be included in the curriculum of studies of each discipline at the undergraduate level and professional bodies like the NIA, NIOB, the Nigerian Institution of Estate Surveyors and Valuers, NSE and NIQS can include some of these courses in their professional competence examinations. This paper thus aims to address gap between academic quantity surveying and quantity surveying in practice from the light of QSs productivity in construction industry. In this paper, historical development of quantity surveying education and quantity surveying in practice were first presented, as backgrounds underlying the essence of the focus of this paper. The factors affecting Qs education elicited from the literature were assessed in light of their relationship and significance to quantity surveying in practice in Nigeria. The assessment was carried within the boundaries of the defined methodology, upon the findings revealed, conclusions and recommendations were made.

\section{METHODS}

The study adopted a quantitative survey approach with questionnaire as the research instrument. The targeted population were registered quantity surveyors in Ondo State that are either practicing within the construction industry or are within the academic system. Preliminary survey shows that there are 73 registered Quantity surveyors as at the time of conducting the research and this form the total population of the study. Census sampling was adopted since the total population fall within a manageable size. The questionnaire used was structured into two sections. Section A contains the background information section that addresses type of field of academics or practice/field, while section B addresses the research questions. A Likert scale of 1 to 5 was employed, with 5 being very high, 4 being high, 3 being average, 2 being low and 1 being very low. A total of 70 questionnaires were administered through hand delivery and email as it was difficult to reach three others of the identified Quantity surveyors. Out of the 70 questionnaires distributed, 52 were retrieved with 2 of them being invalid.

The data collected on the background of the respondents was analyzed using percentage while Mean Item Score and was used to analyze the data gathered on the research objective. The 
reliability of the questionnaire was test using Cronbach's alpha test which gave an alpha value of 0.819 and 0.717 respectively for the factors addressed, thus implying high reliability of the questionnaire used. Mann- Whitney U- Test a non-parametric test was used in determining consistency in the opinion of the different professionals sampled. This was adopted because it is most suited for testing the significant difference or relationship existing in the view of two groups of respondents (Pallant, 2005).

\section{HEADINGS AND LAYOUTRESULT AND DISCUSSION}

Analysis carried out indicates $30.8 \%$ of respondent are in academic field only while practicing respondent are $62.9 \%$ Also in terms of education, HND holder are $30 \%$ of the respondents, the B.sc/B.Tech are $36 \%$ are while the P.gd/M.Sc are $32 \%$ of the respondent. Twenty five percent $(25 \%)$ of the respondents have less than 5 years of experience, $66 \%$ of the respondent have between 5-10 years' experience while $10 \%$ of the respondent have between $10-15$ years' experience. This result implies that the respondents for the study have considerable amount of experience within the Quantity surveying profession to give significant contribution to the subject of discussion.

Result in Table 1 shows the mean score as well as the $\mathrm{z}$-value and significant $\mathrm{p}$-value derived from Mann-Whitney U Test for the factors serving as gap between Academic QS and QS in practice. Mann-Whitney test is used to ascertain if there is a significant difference in the view of professionals (practicing and those in academics) against factors serving as gap. Result in Table 1shows that that at $95 \%$ confidence intervals, there is no significant difference in the view of both sets of Quantity surveyors with regards to all the assess factors causing gap between Academic QS and QS in practice except for "discipline in academic training ( $p$ value 0.050)" as the all have a significant $\mathrm{p}$-value of above 0.05 ., Therefore, the result from the mean score can to a large extent be upheld as little variation exist in the opinion of the respondents.

In table1, it was also identified by respondents that more theoretical knowledge than practical, inadequate school curriculum, and slow adoption of innovations are also important factors serving as cause of gaps, MIS 4.37, 3.96, 3.9 and, respectively. Following closely, it is seen that inadequate trained personnel, (MIS 3.88,), discipline in academic training (MIS 3.38) and new IT innovation is restricted to Academic research with MIS 3.35.The least factors are identified as new IT innovation is restricted to Academic research with MIS 3.06, and MIS 2.88 and respectively.

These findings are in accordance with Souza and Thwala (2013) who recognized that employers in South Africa face students who are not well equipped for workplace and students equally have challenges with their taught program. Similarly, in Sri-Lanka, Quantity Surveying education is not meeting up with industry expectation because, there is a need for Quantity Surveyors' formal education to account for basic knowledge (Yogeshwaran et al., 2018). This is necessary in order to prepare them for what they must accept as their primary function (Olanrewaju and Anahve, (2015). Closely, Nigerian quantity surveyors of older generation were more of experts in the costing, cost monitoring and control as it relates to building projects which they were respected for by their allied professionals (Olusoga, 2006). Also, some skill or knowledge sect of Quantity surveying students are either same or inferior to their predecessors in Hong Kong construction industry (Wong et al, 2007). 
From extensive related work, a list of possible solution to bridging the gap between academic QS and QS in practice were identified. The consistency in opinion of respondent was ascertained using Mann-Whiney U-test with Null Hypothesis stating that there is no significant difference between the professionals (Academic and Practice) and identified solutions, while the alternate hypotheses has it that there is a significant difference between the professionals (Academic and Practice) and identified solutions. According to table 2 below, all variables have p-value $>$ than 0.05 alpha value at $95 \%$ confidence interval, this shows that it is not statistically significant.

Table 2 also shows that frequent organization of workshop, lectures and seminars, openness to new innovations, equilibrium of theoretical and practical knowledge are the most important variables identified to be able to bridge gap between academic QS and QS in practice. They have MIS of 4.56, 4.33, 4.31 .The next important factors are learning on job (MIS 4.20), higher educational qualifications, (MIS 4.23) and proper diffusion of new IT innovations with MIS 4.17. The least factors are Aligning academic and field concepts (MIS 4.06) and Extension of SIWES training MIS 3.88. This agrees with the findings that technology has effect on clients need and project delivery method since there is an attitude towards ICT by practicing quantity surveyors (Odubiyi and Oke 2016; Usman, 2012). Also, construction professionals should be more flexible and open to a new innovation by technology due to the present age of globalization (Wong et al., 2007).

Table 1. Factors serving as gap

\begin{tabular}{lcccc}
\hline Variables & Mean & Rank & Z-value & P-value \\
\hline More theoretical knowledge than practical & 4.37 & 1 & -1.452 & 0.146 \\
Inadequate school curriculum & 3.96 & 2 & -0.868 & 0.386 \\
Slow adoption of innovations & 3.90 & 3 & -1.169 & 0.242 \\
Inadequate trained personnel & 3.88 & 4 & -0.904 & 0.366 \\
Discipline in academic training & 3.38 & 5 & -1.915 & $0.050^{*}$ \\
New IT innovation is restricted to Academic research & 3.35 & 6 & -0.554 & 0.580 \\
Inadequate qualifications & 3.06 & 7 & -0.588 & 0.557 \\
SIWES is short & 2.88 & 8 & -0.798 & 0.425 \\
\hline
\end{tabular}

Table 2. Identified Solutions

\begin{tabular}{lcccc}
\hline Possible Solutions & Mean & Rank & z-value & P-Value \\
\hline $\begin{array}{l}\text { frequent organization of workshop, lectures and } \\
\text { seminars }\end{array}$ & 4.56 & 1 & -0.403 & 0.687 \\
openness to new innovations & 4.33 & 2 & -1.433 & 0.152 \\
equilibrium of theoretical and practical & & & & \\
knowledge & 4.31 & 3 & -0.1755 & 0.861 \\
learning on job & 4.29 & 4 & -0.539 & 0.590 \\
higher educational qualifications & 4.23 & 5 & 0.000 & 1.00 \\
proper diffusion of new IT innovations & 4.17 & 6 & 0.108 & 0.108
\end{tabular}


MOC SUMMIT / MAY 2019

\begin{tabular}{lllll} 
Aligning academic and field concepts & 4.06 & 7 & 0.967 & 0.967 \\
Extension of SIWES & 3.88 & 8 & 0.633 & 0.633 \\
\hline
\end{tabular}

\section{CONCLUSION}

This study set out to address bridging the gap between Academic QS and QS in practice. Using a survey design, the causes of gap and way forward to bridging this gap has been identified. The two categories of respondents( practicing respondents and those in academics) believes that the most important factor that can help and in bridge the gap between QS in Academics and QS in practice is frequent organizing workshop, lectures and seminars which has been identified by past literature. Openness to new innovations, equilibrium of theoretical and practical knowledge, learning on job, acquiring higher educational qualifications, proper diffusion of new it innovations, aligning academic and field concept, and extension of SIWES, are the closely following factors. The study contributes to the body of knowledge as it brings to light the major factors serving as gap between academic and practice Quantity Surveying as well as the possible solutions to bridge the gap in Nigerian construction industry. It recommends that the gap between the two profession divisions should be bridged to allow the proper fulfilment of the original activities of the profession. This work is limited by sample size which calls for a further research.

\section{REFERENCES}

Akintayo, O., Awodele, A., Babatunde, S., and Awodele, P. (2012). "Review of Correlation of Quantity Surveyors' Education." Journal of Education and Practice, 109-117.

Ameh, O.K. and Odusami, K.T. (2014) "The leadership profile of Nigerian construction project managers" Scientia Iranica, Transactions A: Civil Engineering 21(4), 1241-1248.

Heckathorn, D. D. (2011). "Comments: Snowballing versus respondent-driven sampling." Sociological Methodology, 41(1), 355-366.

Jagboro, G.O. (2016). "Unmasking the Tower of Babel and the Scourge of Abandoned Projects in Nigeria. Ile-Ife." Inaugural Lecture series 286. . Ile-Ife, Osun, Nigeria: Obafemi Awolowo University, Ile-Ife.

Odubiyi, T. B. and Oke, A.E. (2016). "Strengths, weaknesses, opportunities and threats of virtual team in Nigerian construction industry." Organization, Technology and Management in Construction, 1-8.

Oke, A.E., Aje, I.O, and Ibironke, T, O. (2013). "Quantity Surveying Profession: Unbundling Latent Competencies." A 2-Day Seminar and Workshop organized by Quantity Surveyors Registration Board of Nigeria (QSRBN) in collaboration with the Nigerian Institute, 2013. Abuja, Nigeria: NIQS.

Oke, A.E., Oladinrin, T.O., and Aje, I.O. (2010). "Perception of Construction Professionals to the Performance of Nigerian Quantity Surveyors.” Journal of Building Performance, 1-9.

Olanrewaju, A., and Anahve, P.J. (2015). "Duties and responsibilities of quantity surveyors in the procurement of building services and Engineering." Creative Construction Conference 2015 (CCC2015) Procedia Engineering. 352-360.

Olanrewaju, A., Anahve, P., and Abdul-Aziz, A. (2012). "The Nigerian Quantity Surveyors in an emerging market." CIB.1-12. 
Olusoga, J. R. (2006). "Ethical issues and the challenges in construction professionals' service delivery." Nigerian Institute of Quantity Surveyors, Ondo state chapter. Akure.

Pallant, J. (2005). "SPSS Survival Manual: A Step by Step Guide to Data Analysis Using SPSS for Windows (Version 12). Allen \& Unwin, Crow's Nest. NSW, Australia.

Paranawithara, K. (2014). "Quantity Surveying Education in Sri-Lankan State Universities." SLQS-UAE 30th Get-together.

Souza, P.N., and Thwala, W.D. (2013). "Master's Thesis. Assessment of Quantity Surveying Curriculum development in South Africa." Gauteng, South Africa: Faculty of Engineering and Built Environment University of Johannesburg.

UNESCO/UNDP. (1987). "Development of Quantity Surveying courses: Project Findings and Recommendation." United Nations Development Program. Paris.

Usman, N.S I., \& Yahaya, A.Z. (2012). "Indolent Disposition towards ICT Acceptance among Practicing Quantity Surveyors in Nigeria." Acta Technica Corviniensis - Bulletin Of Engineering, 75-79.

Wong, J.M.W, Wong, F.K.W., and Eddie C.M. Hui, E.C.M. (2007). "A Study to Improve Higher Education for Surveying Professionals in Hong Kong." Journal for Education in the Built Environment, 2(1), 76-89.

Yogeshwaran, G., Perera, K.K.S, Mahendrini, M.R., and Ariyanchandria, F. (2018). "Competencies expected of graduate Quantity surveying working in developed countries." Journal of Financial management of Property and construction, 23(2). 